\title{
Training Needs of International Medical Graduates [IMGs] in Psychiatry*
}

\author{
Milton Kramer \\ Psychiatry Department, College of Medicine, University of Cincinnati, Cincinnati, Ohio, USA \\ Email: milton1929@yahoo.com \\ Received 20 July 2014; revised 15 August 2014; accepted 10 September 2014 \\ Copyright (C) 2014 by author and Scientific Research Publishing Inc. \\ This work is licensed under the Creative Commons Attribution International License (CC BY). \\ http://creativecommons.org/licenses/by/4.0/

(c) (i) Open Access

\begin{abstract}
The potential shortage of psychiatrists over the next 5 - 10 years has focused attention on the need to recruit more IMGs to fill the needs rather than use nurse practitioners or physician assistants. IMGs make up about $1 / 3$ of first year psychiatry residents. These individuals have been found to provide services to the poor, the elderly and the psychotic. The quality of their medical work has been found to be satisfactory. The training needs of these physicians require an understanding on the part of their teachers that they come from cultures with different values that we have. The extended families of these primarily Asian residents clash with our strong commitment to individualism. It leads to a We-self rather than our I-Self. This difference coupled with the stress of leaving to come to a new culture is a great stress. Their exposure to psychiatry has been limited. They request and need more interview demonstration and practice, ore feedback and examinations. They should have help in accent reduction. They should be exposed to the working of the hospital by sitting on departmental and hospital committees. The faculty should extend their social opportunities and work as mentors on joint projects. Courses on the history of American culture should be taught. Psychotherapy for them should be encouraged as well as teaching medical ethics. They must become the major educational concern for the department that they are in.
\end{abstract}

\section{Keywords}

International Medical Graduates, Psychiatric Residents, Education

\section{Introduction}

We are at a time in American Medicine when we will be experiencing an extreme shortage of physicians [1]. The consensus is that we will be 90,000 physicians short by 2020 and 200,000 short by 2025. We had an esti-

*Presented 2014 at APA IMG Summit: Global Psychiatric Education and Practice: Role of IMGs in American Psychiatry; Panel II: IMGs in the U.S. 
mated 45,000 psychiatrist in 2000 and would need an additional 34,700 psychiatrists to reach an optimal level for a population of 310,000,000 [2]. The physician shortage can only be addressed by increasing the number of training positions available and allowing more International Medical Graduates [IMGs] to enter the United States.

The recommendation for seeking a solution to our manpower needs by increasing IMGs entry into our medical system, particularly in psychiatry, is enhanced by the unique roles IMGs which have played in psychiatry: they serve the underserved both as trainees and practitioners meeting the needs of specific, primarily immigrant populations but also the poor, the psychotic, and the elderly [3]. And they are an increasing percentage of psychiatrists in the United States [4]. IMGs are 26\% of the members of the American Psychiatric Association and $33 \%$ of psychiatric residents [5]. It is not that American psychiatry is just becoming a specialty with more women, it is becoming international as well [6]. It is essential that we be particularly concerned with the learning processes of IMGs in psychiatry because of the contributions that they make to patient care.

\section{Discussion}

Recognizing the special needs of IMGs encourages training programs to consider techniques to meet the needs of this growing number of residents and future colleagues. The recommendation of IMGs to their teachers [7] is for more structured teaching with verbal recitation of assigned reading along with the liberal use of demonstrations, supervision, examinations and feedback. I believe that the introduction of psychological concepts early in the training program and in every doctor-patient interaction may facilitate a greater awareness of these issues earlier in training before evaluative patterns become fixed and patients are seen only from a biological perspective.

A series of caveats are in order before proceeding with a discussion of IMGs in psychiatry. It is important to recognize that IMGs are not a homogeneous group [6]. It has been estimated that $41 \%$ are from Asia. The quality of the medical skills of more recent IMGs has improved as measured by the scores they obtain on the Clinical Skills Assessment (CSA) examination and has begun to approach that of U.S. medical school graduates (USMGs), $89 \%$ compared to $80 \%$ [8]. In practice, they provide services comparable in effectiveness to USMGs [9] [10].

The learning needs of IMGs must be individualized. We need to keep in mind that these residents have come from very different cultures with very different values. Their conceptualizations of the nature of man may present unique problems and challenges in the learning process [11] [12].

Suggesting that a group has special needs unfortunately implies that the group is being seen as inferior rather than as different and immediately raises the specter of bias, especially if done by a nonmember of the group. This makes a discussion of the issues difficult, if not, at times, impossible. To put the problem in perspective, it is essential for Americans to be reminded that almost all the major innovations in psychiatry were made by non-Americans [13]-[15]. Ramon y Cajal, a Spaniard, described the network rather than syncytial nature of the central nervous system. Convulsive therapy was first described by Meduna, a Hungarian, and Cerletti and Bini, both Italians. Psychopharmacology was inaugurated by the observations of Denniker and Delay in France. Freud, an Austrian, and Pavlov, a Russian, introduced the bases for psychodynamic and behavioral therapies. Humane treatment approaches were introduced by Pinel in France and Tuke in England, while community psychiatry and treatment were developed in Belgium at Gheel. Understanding the role of neurotransmitters in psychiatric illness was dependent on the discovery of intracellular staining techniques by Dahlstrom and Fuxe in Sweden. It was the impact of the immigrant European analysts, mostly IMGs, before and after the Second World War that determined the nature of psychoanalysis and psychodynamic psychotherapy in the United States. And lastly, the work of Kraeplin, a German, was the intellectual base for the turn to biological psychiatry around 1970 . The educational problems we are addressing have to do not with issues of intelligence or creativity, but with the demands of learning how to view the world differently in a new cultural context [16]. Very little has been written about the educational issues that may be unique for IMGs [17]. The focus has been on the barriers that exist for IMGs who come for training and remain to practice in the U.S. These barriers are formidable and have been the focus of significant effort by many individuals to remove or reduce them [4] [18].

It is important to point out at the outset of our discussion of the educational problems that confront IMGs that they and USMGs have a great deal in common [4] [19] [20]. Both groups have completed medical school, are of above average intelligence, persevering and ambitious, and upwardly mobile in their aspirations. IMGs, however, have a series of concurrent personal issues [4] [19]-[21] having to do with immigration, such as feeling lonely 
and socially isolated, experiencing a decrease in status with its accompanying diminishment of self-esteem, concerns related to the family they left behind and the family by marriage that they may have brought with them, lack of money, and worries related to the vagaries of their visa status. Salman Akhtar [16] discusses with great sensitivity the psychosocial impact of immigration on the immigrant's identity. Group and individual social interaction of residents with faculty is enormously valuable in reducing the sense of isolation.

The specific concerns that have been expressed about IMGs include the quality of their medical education and especially their limited psychiatric experience and knowledge [4] [19] [20]. The contact with psychiatric patients may be as little as a one-day visit to a mental hospital. They may have had little on-service responsibility in medical school, with psychiatric exposure being for some IMGs only a series of lectures. The idea of being part of a team is not congenial to residents who come from hierarchically ordered cultures. IMGs are said to be poor at relating to other disciplines and less effective than USMGs in teaching medical students. They believe they cannot complain or they will be terminated, which for many would lead to a forced return home because of their visa status. IMGs feel powerless because they have only themselves to rely on in their working with patients who may be afraid of them, challenge them, or reject them. IMGs have their identity problems compounded by the loss of medical rituals (e.g., white coats and ward rounds).

The ideal psychiatric resident is seen as warm, friendly, open, active, independent, and inquisitive, whereas the prototypical IMGs is seen as passive, inhibited, reserved, and rigid, with greater difficulty in allowing the use of their imagination [20]. These unfortunate stereotypes have a basis in the value system of American culture. IMGs are often treated as second-class trainees and educationally neglected [20]. They may be overtly rejected and used only to meet service needs, with the rationalization that they should be grateful they were given a position. A more subtle but equally pernicious rejection is to provide very little education on the basis that not much can be expected from IMGs. At the other end of the spectrum, there are those who deny the reality of difference and see IMGs as like all other residents and without special needs. They ignore or minimize the struggles that IMGs experience rather than help to ameliorate them. Teachers must help integrate their trainees into the mainstream of American psychiatry, e.g. by encouraging their going to professional meetings and seeing they are appointed to departmental and hospital committees.

The central role of language and culture lies at the heart of the learning problems that IMGs have in general in becoming psychiatrists in the American context and more particularly in learning psychological theory and therapy. Without a mastery of the language, both formal and informal (i.e., slang and idioms), and a reduction in accent so that their spoken communication is readily understood, IMGs may not understand their patients and teachers and not be understood by them.

Knowledge of the culture in which the exchange takes place often is essential for understanding as Hirsch and colleagues (2002) pointed out in their book, The New Dictionary of Cultural Literacy: “They (IMGs) may have the words but not the meaning”. The lyrics but not the melody.

In some other cultures, the role of parents and the nature of the child-parent relationship are different from what we hold as the norm orideal in the U.S. Attitudes toward authority and the constraints of obedience vary significantly. Gender roles and inter gender behaviors may be different from ours. The aged are seen as a source of wisdom and entitled to respect. America has been described by an IMG as dangerous, the people as materialistic and self-absorbed, caught up in superficial relationships and neglectful of the poor, children, and the elderly [4]. IMGs may have a different view of the nature of man, a different value system, a different Weltanschauung.

It is the special focus on the individual and individualism that may be said to characterize American if not all of Western society, but developed to its fullest in the U.S., The demand on each of us is to develop ourselves to the fullest. The clarion call to the young is to "follow your bliss" [22]. The Culture of Narcissism, by Christopher Lasch [23], may be more than just a book title and the narcissistic personality may be more than just a DSM 5 classification (2013). A heightened narcissism may capture something central to our cultural values, which is expressed in our psychology. Many IMGs do not come from cultures that share our commitment to individualism. They view behavior and achievement from a different perspective.

Vozzola [23] has summarized, from a psychological point of view, the major foundational moral themes of several societies. The American moral themes are personal liberty, privacy and equality. In contrast, The Indian themes are sanctity/pollution, chastity and respect. China's moral themes are historically Confucian, namely that humans are born good, not the Christian view of man being born with original sin. The Chinese Communist party fosters obedience and that behavior should foster economic development. Chinese culture is shame based, as are other Eastern cultures, with no emphasis to promote critical thinking or meeting individual needs. For 
Muslims faith and moral behavior are the same. God disclosed forbidden [Haram] and permitted behavior [Halal]. Moral education is not to develop personal autonomy but to carry out Muslim law [Sharia], and to submit [Islam]. Latin America's civil morality was shaped by the independence struggles of the early $20^{\text {th }}$ century. Morality is social customs and traditions and ethics is a reflection of those traditions. In sub-Saharan Africa, Afro-communitarianism is the alternative to Western justice and care. A person is a person through other persons. Morality is relational. We punish for retribution and deterrence, they prescribe reconciliation or reparation of broken relationships. Must be concerned about others and the self is defined that encompasses that encompasses morality for everyone as part of a group. "I am because we are". It is clear that no single value appears that is morality for everyone although do no harm and act that you care come very close.

In understanding our trainees, one needs to understand the structure and vicissitudes of their family constellation. The family constellation that is described in the West is the nuclear family. However, for many of our trainees, the model is the extended family, not the nuclear family. The extended family structure, which is the mode in Asia, leads to intense emotional interconnectedness that deeply affects their members. These intimate relationships in the extended family are hierarchical in nature, in which the superior is expected to be nurturing and responsible and the subordinate is deferential and obedient. In these circumstances, the expectation that the student therapist will see the learning relationship to his or her supervisor as egalitarian seems hopelessly naïve. The supervisor is expected to be nurturing, empathically responsive, responsible, and supportive of the student's self-esteem. Maintenance of self-esteem may take precedence over the truth in what may be seen as a contextual conscience. The supervisor may be seen as a family elder, a mentor, or a teacher who is expected to give advice and is hard to criticize directly [24]-[28].

From such an extended family constellation with its attendant expectations and experiences arises a selfstructure that is of a familial-group nature and not an individualized self. It is more a We-self than the I-self that is seen in the West. When the self is of a we-type, there are increased concerns about self-esteem, greater dependency and interdependency, a dual self-structure, social and secret, which supports the highly situational conscience of the We-self with its contextual construction of truth. The search for individuality, self-fulfillment, and freedom from parental control that might be seen as a general goal of therapy is going to be seen as selfish, irresponsible, and disobedient by IMG residents with the values that accompany being raised in an extended family. The confrontations with one's own beliefs necessary to becoming a psychiatrist/therapist are more difficult as access to the secret self, make holding contrary views less disturbing and a commitment to the unity and consistency of the personality less necessary.

Roland [25] believes we listen to our patients, and I would add our trainees, based on our own culture. Our norms may view Asian values such as dependency and interdependency, deference and receptivity to superiors, communication by indirect techniques, maintaining and enhancing self-esteem at all costs, and seeing truth as situational as inferior. We may cling to our values of independence and autonomy, self-assertiveness and selfpromotion in egalitarian relationships, verbal articulateness and forthrightness, and frank criticism in expressing the truth as superior.

Given the extent to which individualism and the nuclear family are defining themes of American culture, not understanding this centrality may become a stumbling block for many IMGs in internalizing a system of values at odds with their core beliefs. The awareness of these issues by supervisors of residents from cultures with extended families may alert the supervisor to some of the sources of the learning problems his supervisee's may be having in becoming a psychiatrist.

How might we attempt to meet the educational challenge that IMGs present in psychiatric residency? The participation of psychologically informed psychiatrists as paid and volunteer faculty in residency programs is to be promoted. Residency programs need to become more receptive to the participation of volunteer faculty.

The psychiatric resident needs more experience in treating patients in psychodynamic-psychotherapy and needs more supervision informed by a recognition of the cultural dissonance the IMGs may be experiencing. A psychotherapeutic experience for residents is to be encouraged. Psychological theory and understanding need to be introduced from the start of the residents' experience and applied in non-psychotherapy contexts (e.g., medication follow-ups and inpatient care). Residents must be provided with courses in American culture that deal with the values and beliefs that underpin the attitudes and behaviors of Americans and that are linked to the history of the American people. Language adequacy and accent reduction must be guaranteed. Structured instruction with verbal recitation, written exams, and explicit feedback, the value of which was demonstrated in a program helping individuals who failed the boards to pass them [29] needs to be coupled with an increase in dem- 
onstration and practice interviews. It is incumbent upon us to understand the cultural sources of the values and needs of our residents to enhance their learning experience.

Mentoring by interested faculty is to be encouraged with the goal of facilitating the residents' entry into the mainstream of American psychiatry. Mentoring which involves working together on a joint project is extremely valuable For example, my Maimonides experience-working together over a 4 years period with 27 residents lead to 31 local talks, 6 regional presentations and 19 national ones and 9 publications. Six of the groups are currently in academic careers.

\section{Conclusion}

Professionalism, one of the core competencies that residents must achieve, requires special attention in the training of IMGs. Not all countries have the same standards and do not share the same values. Those from Asia [30] and Africa [31] are least likely to aspire to the same medical values while those from the English speaking countries [32] are more likely to have values similar to ours. We are at a time when our own standards are in flux making the understanding even more difficult. The literature is directed at professionalism education for medical students more than to residents. In clinical practice the primacy of the patient is not a universally held view, but in resident education the primacy of the student-resident must be our view.

\section{Conflict of Interest}

The author states that there is no conflict of interest.

\section{References}

[1] Alberti, M. (2013) Warnings of Doctor Shortage Go Unheeded/Remapping the Debate: Asking Why and Why Not. http://www.remappingdebate.org./article warning-doctor shortage-go-unheeded-1-3

[2] Carlat, D. (2010) 45,000 More Psychiatrists, Anyone. Psychiatric Times. http://psychiatrictimes.com/blog/couchincrisis/content/article/10168/1566084

[3] Blanco, C., Carvalho, C., Olfson, M., Finnerty, M. and Pincus, H. (1999) Practice Patterns of International and U.S. Medical Graduate Psychiatrists. American Journal of Psychiatry, 156, 445-450.

[4] Rao, N. (1999) International Medical Graduates. In Kay, J., Silberman, E. and Pessar, L., Eds., Handbook of Psychiatric Education and Faculty Development, American Psychiatric Association, Washington, DC, 125-142.

[5] American Psychiatric Association (2013) Diagnostic and Statistical Manual of Mental Disorders. 5th Edition, APPI Press, Washington, DC.

[6] Gangure, D. (2002) International Medical Graduates in American Training Programs. XII World Psychiatry Congress of Psychiatry.

[7] Knoff, W., Oken, D. and Prevost, J. (1976) Meeting Training Needs of Foreign Psychiatric Residents in State Hospitals. Hospital and Community Psychiatry, 27, 35-37.

[8] Whelan, G., Gary, N., Kostis, J., Boulet, J. and Hallock, J. (2002) The Changing Pool of International Medical Graduates Seeking Certification in US Graduate Medical Education Programs. JAMA, 288, 1079-1084. http://dx.doi.org/10.1001/jama.288.9.1079

[9] Mick, S. and Comfort, M. (1997) The Quality of Care of International Medical Graduates. How Does It Compare to That of U.S. Medical Graduates. Medical Care Research and Review, 54, 379-413. http://dx.doi.org/10.1177/107755879705400401

[10] Norcini, J., Boulet, J., Dauphinee, W., Opalek, A., Kranz, I. and Anderson, S. (2010) Evaluating the Quality of Care Provided by Graduates of International Medical Schools. Health Affairs, 29, 1461-1468. http://dx.doi.org/10.1377/hlthaff.2009.0222

[11] Kramer, M. (2005) The Educational Needs of International Medical Graduates in Psychiatric Residency. Academic Psychiatry, 29, 322-324. http://dx.doi.org/10.1176/appi.ap.29.3.322-a

[12] Kramer, M. (2006) Educational Challenges of International Medical Graduates in Psychiatric Residencies. The Journal of the American Academy of Psychoanalysis and Dynamic Psychiatry, 34, 163-171. http://dx.doi.org/10.1521/jaap.2006.34.1.163

[13] Alexander, F. and Selesnick, T. (1966) The History of Psychiatry. Harper and Row, New York.

[14] Kandel, E. and Schwartz, J. (1985) Principles of Neural Science. 2nd Edition, Elsevier, New York. 
[15] Shorter, E. (1997) A History of Psychiatry. Wiley, New York.

[16] Akhtar, S. (1999) Immigration and Identity. Aronson, Northvale.

[17] Weintraub, W. (1997) International Medical Graduates as Psychiatric Residents: One Training Director's Experience. In: Husain, S., Munoz, R. and Balon, R., Eds., International Medical Graduates in the United States, American Psychiatric Press, Washington DC, 53-64.

[18] Balon, R. (2000) Practice Patterns of International Medical Graduates. American Journal of Psychiatry, 157, 485. http://dx.doi.org/10.1176/appi.ajp.157.3.485-a

[19] Brody, E., Modarressi, T., Penna, M., Jegede, R. and Arana, J. (1971) Intellectual and Emotional Problems of Foreign Residents Learning Psychiatric Theory and Practice. Psychiatry, 34, 238-247.

[20] Char, W. (1971) The Foreign Resident: An Ambivalently Valued Object. Psychiatry, 34, 234-238.

[21] Beaubrun, M. (1971) Foreign Medical Training and the "Brain Drain”. Psychiatry, 34, 247-251.

[22] Campbell, J. (1988) The Power of Myth. Doubleday \& Co., New York, 117.

[23] Lasch, C. (1991) The Culture of Narcissism. Norton, New York.

[24] Vozzola, E. (2014) Moral Development: Theory and Applications. Routledge, New York.

[25] Roland, A. (2003) Psychoanalysis across Civilizations: A Personal Journey. The Journal of the American Academy of Psychoanalysis and Dynamic Psychiatry, 31, 275-295. http://dx.doi.org/10.1521/jaap.31.2.275.22118

[26] Desai, P. and Coelho, G. (1980) Indian Immigration in America: Some Cultural Aspects of Psychological Adaptation. In: Seran, P. and Eames, E., Eds., The New Ethics: Asian Indians in the United States, Praeger, New York, 363-386.

[27] Desai, P. (1982) Learning Psychotherapy: A Cultural Perspective. Journal of Operational Psychiatry, 13, 82-87.

[28] Lijtmaer, R. (2001) Countertransference and Ethnicity: The Analyst's Psychic Changes. Journal of the American Academy of Psychoanalysis, 29, 73-83. http://dx.doi.org/10.1521/jaap.29.1.73.17194

[29] Rao, N. (2005) Personal Communication One Day Training to Help Pass Psychiatric Boards. Unpublished Paper.

[30] Plotnikoff, G. and Amano, T. (2007) A Culturally Appropriate, Student Centered Curriculum on Medical Professionalism. Successful Innovations at Keio University in Tokyo. Minnesota Medicine, 90, 42-43.

[31] Van Rooyen, M. (2004) The Views of Medical Students on Professionalism in South Africa. South African Family Practice, 46, 28-31. http://dx.doi.org/10.1080/20786204.2004.10873030

[32] Campbell, J., Roberts, M., Wright, C., Hill, J., Greco, M., Taylor, M. and Richards, S. (2011) Factors Associated with Variability in the Assessment of U.K. Doctor's Professionalism: Analysis of Survey Results. British Medical Journal, 343, d6212. http://dx.doi.org/10.1136/bmj.d6212 
Scientific Research Publishing (SCIRP) is one of the largest Open Access journal publishers. It is currently publishing more than 200 open access, online, peer-reviewed journals covering a wide range of academic disciplines. SCIRP serves the worldwide academic communities and contributes to the progress and application of science with its publication.

Other selected journals from SCIRP are listed as below. Submit your manuscript to us via either submit@scirp.org or Online Submission Portal.
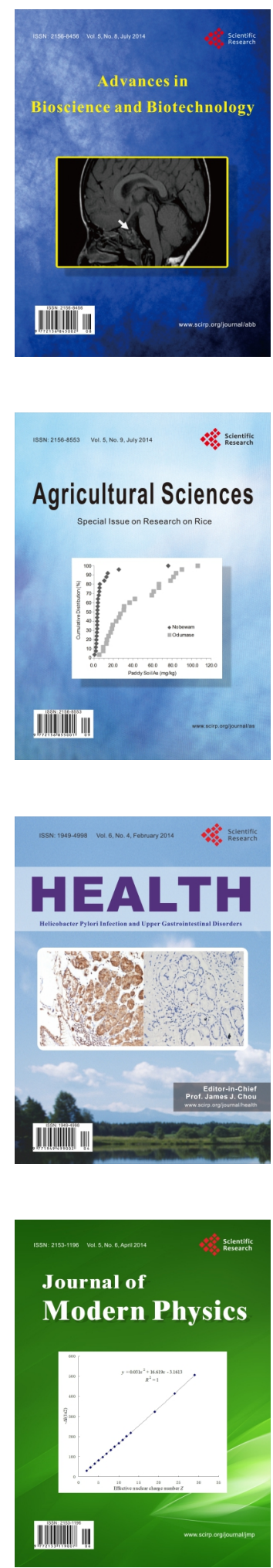
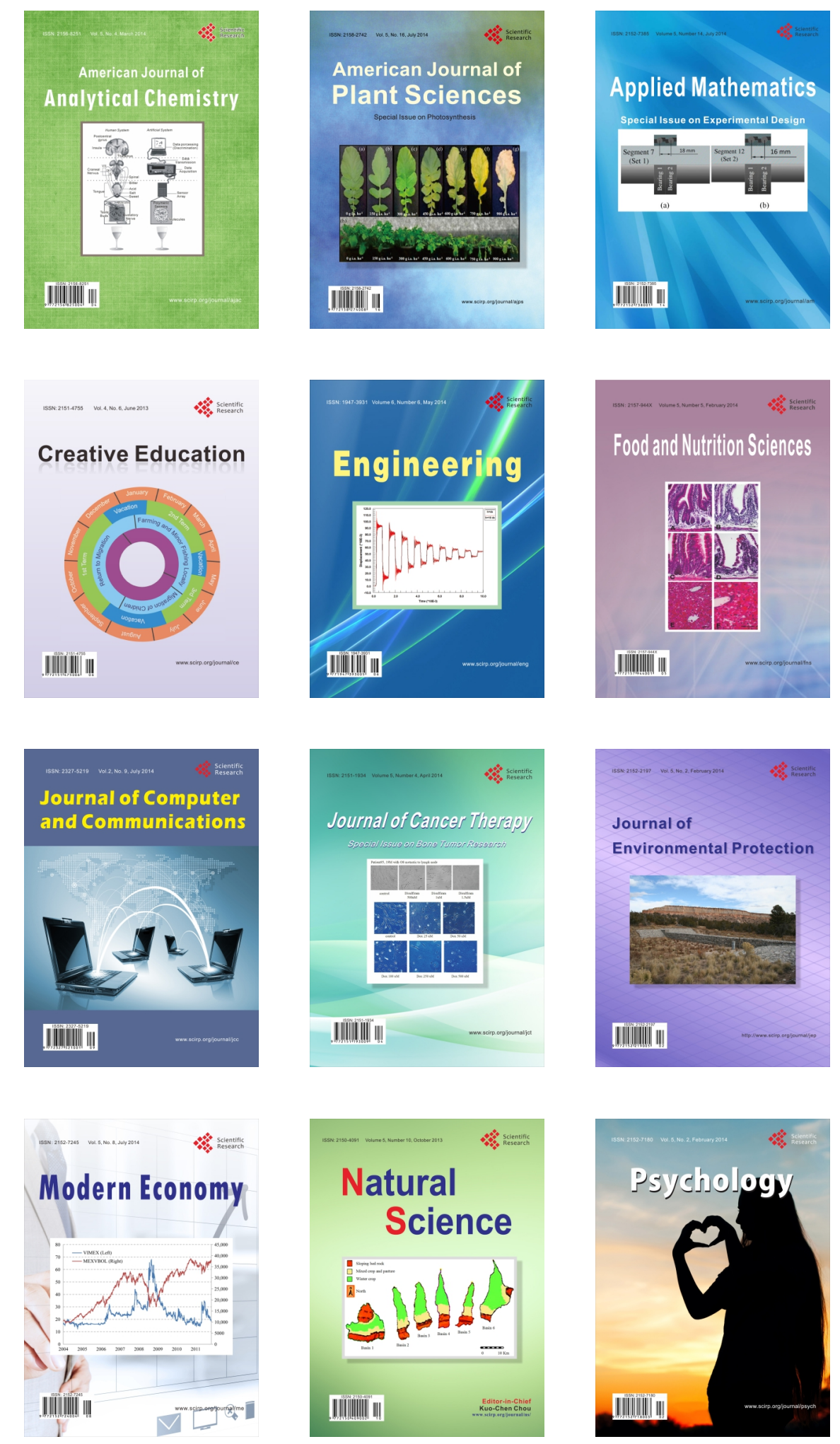